\title{
Strategic Pricing: A Game In Market Economics
}

Tarek H. Selim, American University, Cairo, Egypt

\begin{abstract}
In this paper, game theory is applied to the case of price wars in a market scenario game towards a converging solution of Nash equilibrium. This is done using the famous Bertrand Game, starting first with a simple version of a game involving two players with undifferentiated products who move simultaneously by merely choosing their prices, and then proceed by extending the market scenario to a Differentiated Bertrand Game. The market scenario is based on two main rivals. "LOCAL" player is faced by a lower-priced "ASIAN" player who has a significantly lower quality product. Price wars dictate market outcomes. Implications of the game reveal interesting, but rather unexpected, results. Specifically, it is shown that resorting to a price war alone is not the optimum choice by the LOCAL player. Rather, the incumbent must not lower his price, even if faced by a lower priced competitor. This runs in contrast to traditional price war theory. The introduction of lower priced substitutes do not reveal price reduction of the incumbent firm. A unique Nash equilibrium arises when the LOCAL player differentiates his products and charges higher prices compared to the ASIAN player. Consequently, price competition and price wars, when augmented by differentiated aspects of product quality, do not lead to price convergence nor necessarily lead to price reductions over time.
\end{abstract}

Keywords: Game Theory, Bertrand, Product Differentiation, Price Wars

\section{INTRODUCTION}

ntense competition among business organizations, made even fiercer by budget constraints, production costs, limitations imposed by consumer preferences, open markets, and rapid technological change, has made it essential for business firms to make sound production decisions. Such decisions involve several tradeoffs, for example a higher quality product would involve charging a higher price which represents an opportunity cost to the firm. This is especially true when such a firm is competing with a lower quality, lower-priced product, in a competitive price war environment.

In this paper game theory is applied to the case of price wars in a market scenario game, where a "LOCAL" producer faces fierce competition from an "ASIAN" producer. Competition is based on price as the ASIAN producer provides significantly lower quality products at prices slightly lower than those offered by the LOCAL producer. Results show that resorting to a price war alone is not the optimum choice by the LOCAL producer. Rather, the incumbent must not lower his price, even if faced by a lower priced competitor, but must educate his customers on the higher quality of his products. This runs in contrast to traditional price war theory. The introduction of lower priced substitutes do not reveal price reduction of the incumbent firm. Hence, price competition and price wars, when augmented by differentiated aspects of product quality, do not lead to price convergence nor necessarily lead to price reductions over time.

\section{THE X-MARKET}

The X-market is dominated by few LOCAL producing firms, which will be grouped as 'LOCAL Player' for simplicity in applying game theory. Quality and prices of locally produced products are almost within the same range, and variations between them are minimal and insignificant. There is low brand loyalty among consumers. An inflow of lower-price lower-quality imports, grouped as 'ASIAN Player', will take place. Imported products 
compete with LOCAL production on a price basis, where product quality is considerably lower while prices are slightly lower than locally produced products. It is assumed that inherent deficiencies in imported ASIAN products are not initially detected by consumers. Alternatively, the product is non-durable, hence consumer preferences do not include long term durability as a criteria for purchase. A cheaper lower-quality product has non-zero demand.

Consequently, the X-market is highly price competitive and has low brand loyalty. Free trade is assumed, hence government places no quotas or tariffs on the ASIAN products. Prices are determined through free market forces (supply and demand).

To summarize, the X-market is characterized as (1) highly competitive in prices with threat of substitutes (negative penetration factor), (2) includes aggressive competition between LOCAL products and ASIAN imports, (3) has low brand loyalty (switching costs are not dominant), and (4) exhibits free market forces and no trade restrictions.

\section{THE BERTRAND GAME}

\section{Overview of the Game}

This game involves a 'continuous strategy space', where the strategy spaces are the prices and players move simultaneously. It models a duopoly segmentation of competitive markets (as with the LOCAL versus ASIAN players discussed above) in which two players/firms offer similar products and choose prices simultaneously in competition with each other to sell as much as they can. This is well-known as the 'Bertrand equilibrium' (with variations in Bertrand, 1883, Hotelling, 1920, Akerlof, 1970, Benoit and Krishna, 1987, and Rasmusen, 2007). The model assumes a constant marginal cost, set at $c=K$, and demand is a linear function of the total quantity sold where $Q(p)=A-p$, implying that if $p$ were the lowest possible price, then $q=A-p$ (Rasmusen, 2007, p. 90). Hence, $A$ is the maximum non-usage price and $K$ is the unit cost of production (firms are cost minimizers). Let $A=120$ and $K=12$. This basically implies that the product can be priced as much as ten times its actual cost but not more $(A / K=10)$.

\section{The Structure of the Game}

*Players:

Firms A \& B

*The Order of Play:

A \& B simultaneously choose prices $p_{a}$ and $p_{b}$ from the set $\{0, \infty\}$

*Payoffs:

The payoff function for Firm A is:

$$
\pi_{a}= \begin{cases}\left(120-p_{a}\right)\left(p_{a}-c\right) & \text { if } p_{a} \leq p_{b}, \\ {\left[\left(120-p_{a}\right)\left(p_{a}-c\right)\right] / 2} & \text { if } p_{a}=p_{b}, \\ 0 & \text { if } p_{a}>p_{b} .\end{cases}
$$

Analogously, the payoff for Firm B would be:

$$
\pi_{b}= \begin{cases}\left(120-p_{b}\right)\left(p_{b}-c\right) & \text { if } p_{a} \geq p_{b}, \\ {\left[\left(120-p_{b}\right)\left(p_{b}-c\right)\right] / 2} & \text { if } p_{a}=p_{b}, \\ 0 & \text { if } p_{a}<p_{b} .\end{cases}
$$




\section{Outcome of the Game}

The Bertrand Game has a unique Nash equilibrium, where: $p_{a}=p_{b}=c=12$, with $q_{a}=q_{b}=54$. This is a weak Nash equilibrium because if either player deviates to a higher price, it sells zero quantity as it loses all its customers to its competitor offering the lower price and thus ends up with zero profits (Rasmusen, 2007).

However, to prove the uniqueness of this Nash equilibrium it is useful to divide-up the possible strategy profile space as follows and show that in all other cases deviation will occur:

*If $p_{a}<c$ or $p_{b}<c$ : The firm with the lowest price earns negative profits and could deviate to a higher more profitable price until its demand becomes zero.

*If $p_{a}>p_{b}>c$ or $p_{b}>p_{a}>c$ : The firm with the higher price could deviate to a lower price below that of its rival and increase its payoffs from zero to positive profits.

*If $p_{a}=p_{b}>c$ : In this case one of the firms could profitably deviate to a price less than that of its competitor thus selling all the market quantity instead of half of it, so although marginal profits drop incrementally his total profits rise.

*If $p_{a}>p_{b}=c$ or $p_{b}>p_{a}=c$ : The firm with the price $=c$ could profitably increase its price while maintaining it below that of the other firm, thus increase its payoffs from zero to positive profits.

\section{Bertrand Game Application to the X-Market}

Applying the Bertrand game to the X-market under consideration, each of the two firms (LOCAL and ASIAN) can choose from among three alternative strategies: (i) set price higher than competitor, (ii) set price equal to competitor, or (iii) set price lower than competitor. The equilibrium price is reached when price of both firms are equal to each other, and equal to the marginal cost. Nash equilibrium implies that none of the firms has the incentive to deviate from equilibrium as long as the other firm does not deviate. Economic profits are equal to zero for both players.

The main implications for this game is that since LOCAL and ASIAN players produce similar products with no brand loyalty among consumers, a price war would lead to both players completely defeated. Consequently, both LOCAL and ASIAN players earn zero economic profits and share the market equally.

\section{THE DIFFERENTIATED BERTRAND GAME}

\section{Overview \& Structure}

The Bertrand model explained above has its limitations. It fails to show that profits do not merely arise from the existence of two price-competing players in the market, but because of other additional factors such as product differentiation. The limitation in the above explained Bertrand model is basically attributed to the assumption of identical products offered by both players. Thus the model generates zero profits as incremental price discounts lead to gaining all market customers and total loss on part of the other competitor. However, if customers have some degree of brand loyalty due to product differentiation, the outcome of the game will differ.

Here, the existence of some degree of product differentiation must slightly adjust the demand curves of firms A and B as follows:

$$
\begin{aligned}
& q_{a}=24-2 p_{a}+p_{b} \\
& q_{b}=24-2 p_{b}+p_{a}
\end{aligned}
$$


Marginal costs remain constant and are set at $c=3$. The players, strategy spaces and the order of play are identical to the standard Bertrand Game, however the payoffs now are as follows:

$\pi_{a}=\left(24-2 p_{a}+p_{b}\right)\left(p_{a}-c\right)$

$\pi_{b}=\left(24-2 p_{b}+p_{a}\right)\left(p_{b}-c\right)$

It is an implicit assumption that maximum price can be four times as much as unit cost in this game. This runs in contrast to the ten factor pricing of the standard Bertrand game. Rationally speaking, profit margins would be lower for differentiated competition as compared with homogeneous scale production.

\section{Outcome}

Using linear optimization, firms' payoffs are maximized by choosing prices:

*For Firm A:

The first-order condition:

$d \pi_{a} / d p_{a}=24-4 p_{a}+p_{b}+2 c=0$

Rearranging, we get the reaction / best-response function:

$p_{a}=6+1 / 2 \mathrm{C}+1 / 4 p_{b}=7.5+1 / 4 p_{b}$

* Similarly, for Firm B:

The first-order condition:

$d \pi_{b} / d p_{b}=24-4 p_{b}+p_{a}+2 c=0$

Rearranging, we get the reaction / best-response function:

$p_{b}=6+1 / 2 \mathrm{C}+1 / 4 p_{a}=7.5+1 / 4 p_{a}$

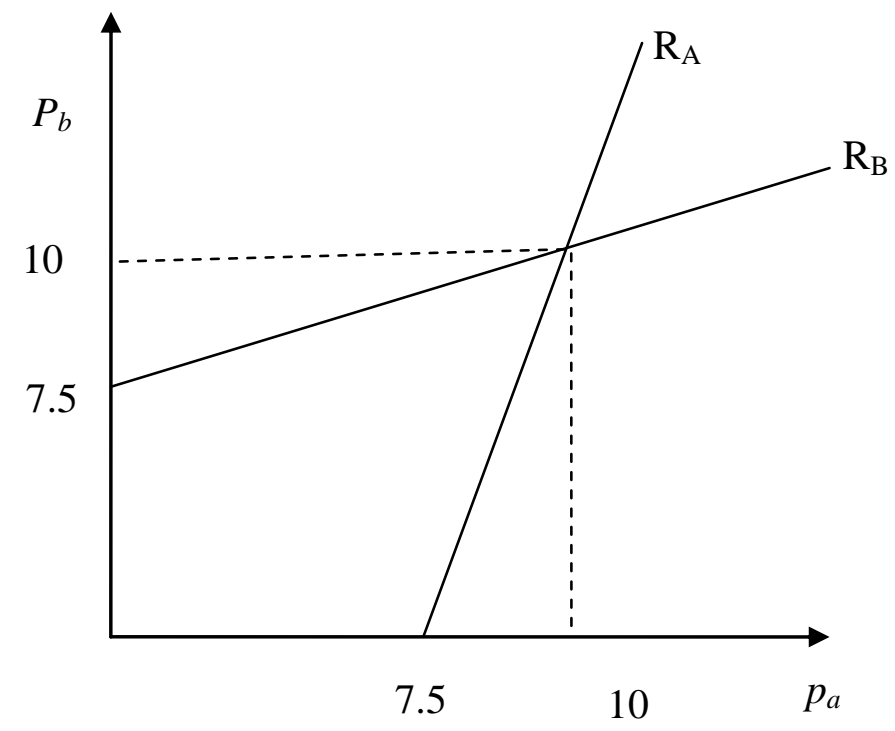

Figure 1: Bertrand reaction functions with differentiated products 
The equilibrium occurs where both reaction functions of Firms A and B intersect, the fact that they cross once indicates that we have again a unique Nash equilibrium, as depicted by Figure 1. The equilibrium lies at the point where $p_{a}=p_{b}=10>c$, and the quantity each firm sells is 14 . This is compared to a quantity of 21 had they chosen prices of $p_{a}=p_{b}=c=3$ (the equivalent unique Nash equilibrium outcome in the standard Bertrand Game).

Overall, in the differentiated game, both players are better off in profits since both have a positive profit margin. Yet, quantity demanded for both players is now lower. Yet, both players charge the same price and have symmetric market shares.

\section{Application of the Differentiated Bertrand Game to the X-market}

The differentiated Bertrand game can now be applied to the X-market. It is worth noting that the greater the (absolute) value in the own price coefficient in the differentiated demand function, the less substitutable are the products offered by the firm. As mentioned above, the coefficient on the own price indicates the substitutability of the products and thus may be a proxy for the degree of product differentiation. Thus adjusting above equations to allow for product differentiation in the sense that Firm A (LOCAL Player) is producing a higher quality product compared to the ASIAN player leads to a new market scenario where:

$$
\begin{aligned}
& q_{a}=24-2 p_{a}+p_{b} \\
& q_{b}=24-3 p_{b}+p_{a}
\end{aligned}
$$

These demand functions in principle imply that the ASIAN player has a higher absolute value of its price coefficient than the LOCAL player, hence price variations would imply that ASIAN products are more substitutable than LOCAL products. Rationally speaking, ASIAN products are of lower quality and hence consumer preferences would prefer LOCAL products over ASIAN if offered at similar prices. Higher quality LOCAL products have more brand loyalty.

The pay-offs for each of the two firms (LOCAL and ASIAN) respectively are:

$$
\begin{aligned}
& \pi_{a}=\left(24-2 p_{a}+p_{b}\right)\left(p_{a}-c\right) \\
& \pi_{b}=\left(24-3 p_{b}+p_{a}\right)\left(p_{b}-c\right)
\end{aligned}
$$

Thus the applied outcome of the game will be:

*For Firm A (LOCAL):

The first-order condition:

$$
d \pi_{a} / d p_{a}=24-4 p_{a}+p_{b}+2 c=0
$$

Rearranging, we get the reaction / best-response function:

$$
p_{a}=6+1 / 2 \mathrm{C}+1 / 4 p_{b}=7.5+1 / 4 p_{b}
$$

*For Firm B (ASIAN):

The first-order condition:

$d \pi_{b} / d p_{b}=24-6 p_{b}+p_{a}+3 c=0$

Rearranging, we get the reaction / best-response function:

$$
p_{b}=4+1 / 2 \mathrm{C}+1 / 6 p_{a}=4+1 / 6 p_{a}
$$


Using substitution, $p_{a}$ at equilibrium will be 8.8 , while $p_{b}$ will be 5.5 .

Therefore,

$p_{a}>p_{b}$

Calculating the pay-offs for each of the two firms, we now get:

$$
\begin{aligned}
\pi_{a} & =(24-2(8.8)+5.5)(8.8-c) \\
& =104.72-11.9 c \\
\pi_{b} & =(24-3(5.5)+8.8)(5.5-c) \\
& =89.65-16.3 c
\end{aligned}
$$

Based on the above, the payoffs of firm A (LOCAL Player) as a result of introducing the differentiated product (in terms of superior quality) are higher than those of firm B (ASIAN Player). However, a higher price, as charged by firm A, is expected to lead to a lower demand and thus, a lower market share. In this regard, demand is estimated as follows:

$q_{a}=24-2 p_{a}+p_{b}=11.9$

$q_{b}=24-3 p_{b}+p_{a}=16.3$

The LOCAL player will charge a higher price and will therefore have a higher profit margin than the ASIAN player. The LOCAL player can signal his degree of differentiation of a higher quality product by charging a higher price. However, the ASIAN player, although producing a lower quality and a lower priced product, will effectively dominate the market.

Hence, for the differentiated game, a Nash equilibrium will be stable if: (1) the LOCAL firm continues to charge higher prices, and (2) the ASIAN firm continues to dominate the market. Yet overall, the LOCAL firm will achieve higher economic profits than the ASIAN firm.

This argument encourages product differentiation (enhanced products). Moreover, the ASIAN player might be expected to react to the LOCAL Player's strategy by increasing their product quality (Tsai, 2003 and Rasmusen, 2007). Therefore, further product differentiation on the part of the LOCAL player to maintain its client base or even expand in the market is rendered essential.

\section{CONCLUSION}

This paper is an analysis of price wars in a differentiated market scenario. Even if faced by lower price competitors, an incumbent firm should not reduce prices. This conclusion runs in contrast to traditional price war theory. On the same line of thought, economists Tom Nagle at Boston Consulting, Adam Brandenberger of Harvard and Barry Nalebuff of Yale argued that "cutting prices to gain market share - as opposed to doing it because of a cost advantage - can often permanently hurt both profits and revenues" (Henderson, 1997). The traditional approach is for firms to invest in process innovation, lower cost of production and thus offer their products at lower prices. An alternative approach would be to invest in product innovation towards a more differentiated product in order to relax aggressive price competition. In that case, they will be able to develop a competitive edge based on higher quality products rather than lower prices. This paper proves that the alternative approach is more worthy.

\section{AUTHOR INFORMATION}

Tarek H. Selim is Associate Professor of Economics, tenure, and Associate Faculty of Business Administration, America University in Cairo (AUC). Dr. Selim is Research Associate of the Alfred P. Sloan Foundation. His core area of specialization is microeconomics of competition. He has published more than forty research articles 
including extensive publications in high quality international journals and has received the University's "School Research Excellence Award" in 2006. Dr. Selim has a Ph.D. in Economics (Fellow) from George Washington University, MBA from Johns Hopkins University, and professional programs from MIT, Harvard, Georgetown, Oxford, and Imperial College.

\section{REFERENCES}

1. Akerlof, G. (1970). "The Market for 'Lemons': Qualitative Uncertainty and the Market Mechanism.” Quarterly Journal of Economics 89: 488-500.

2. $\quad$ Benoit, J-P., and V. Krishna. (1987). "Dynamic Duopoly: Prices and Quantities." Review of Economic Studies 54: 23-35.

3. Bertrand, J. (1883). Reviews of Theories Mathematique de la Richesse Sociale, edited by Leon Walras, and also of Journal des Savants 67: 499-508.

4. Henderson, David R. (1997). "What are Price Wars Good For? Absolutely Nothing”. Fortune, New York, 135(9), p. 156.

5. Hotelling, H. (1929). "Stability in Competition". Economic Journal 39: 41-57

6. Rasmusen, E. (2007). Games and Information: An Introduction to Game Theory, $4^{\text {th }}$ Edition. Blackwell Publishing.

7. Tsai, Weiyu (2003). Essays in New Product Introduction, Washington University Ph.D. Dissertation. 


\section{NOTES}

